\title{
A pan-arctic evaluation of changes in river discharge during the latter half of the 20th century
}

\author{
James W. McClelland, ${ }^{1}$ Stephen J. Déry, ${ }^{2}$ Bruce J. Peterson, ${ }^{3}$ Robert M. Holmes, ${ }^{4}$ \\ and Eric F. Wood ${ }^{5}$ \\ Received 12 January 2006; revised 14 February 2006; accepted 21 February 2006; published 30 March 2006.
}

[1] Several recent publications have documented changes in river discharge from arctic and subarctic watersheds. Comparison of these findings, however, has been hampered by differences in time periods and methods of analysis. Here we compare changes in discharge from different regions of the pan-arctic watershed using identical time periods and analytical methods. Discharge to the Arctic Ocean increased by $5.6 \mathrm{~km}^{3} / \mathrm{y} / \mathrm{y}$ during $1964-2000$, the net result of a large increase from Eurasia moderated by a small decrease from North America. In contrast, discharge to Hudson/James/Ungava Bays decreased by $2.5 \mathrm{~km}^{3} / \mathrm{y} / \mathrm{y}$ during 1964-2000. While this evaluation identifies an overall increase in discharge $\left(\sim 120 \mathrm{~km}^{3} / \mathrm{y}\right.$ greater discharge at the end of the time period as compared to the beginning for Hudson/James/Unvaga Bays and the Arctic Ocean combined), the contrasting regional trends also highlight the need to understand the consequences of adding/removing freshwater from particular regions of the arctic and subarctic oceans. Citation: McClelland, J. W., S. J. Déry, B. J. Peterson, R. M. Holmes, and E. F. Wood (2006), A pan-arctic evaluation of changes in river discharge during the latter half of the 20th century, Geophys. Res. Lett., 33, L06715, doi:10.1029/2006GL025753.

\section{Introduction}

[2] The arctic and subarctic freshwater system is undergoing profound changes $[A C I A, 2005]$. Increasing precipitation at high latitudes, increasing river discharge, and net melting of ice stocks on land and sea all point to an acceleration of the hydrologic cycle [ACIA, 2005; Stocker and Raible, 2005]. However, the trends observed over the arctic and subarctic domain are not evenly distributed nor necessarily of the same sign from region to region. For example, while river discharge to the Arctic Ocean from Eurasia has been increasing [Peterson et al., 2002], discharge to the Arctic Ocean from N. America has not changed significantly [Déry and Wood, 2005] and discharge to Hudson, James, and Ungava Bays (HJUBs) has been decreasing [Déry et al., 2005; Déry and Wood, 2005]. Understanding how these regional findings relate, and in

\footnotetext{
${ }^{1}$ Marine Science Institute, University of Texas, Port Aransas, Texas, USA.

${ }^{2}$ Department of Environmental Science and Engineering, University of Northern British Columbia, Prince George, British Columbia, Canada.

${ }^{3}$ Marine Biological Laboratory, Woods Hole, Massachusetts, USA.

${ }^{4}$ Woods Hole Research Center, Woods Hole, Massachusetts, USA.

${ }^{5}$ Department of Civil and Environmental Engineering, Princeton University, Princeton, New Jersey, USA.
}

Copyright 2006 by the American Geophysical Union. 0094-8276/06/2006GL025753\$05.00 particular to what degree they balance, will help us to sort out the relative importance of climate variability within the arctic and subarctic domain versus increased atmospheric moisture transport from lower to higher latitudes as a consequence of global warming [Cubasch et al., 2001; Stocker and Raible, 2005].

[3] As the arctic and subarctic freshwater system responds to global warming, increasing freshwater fluxes into the Nordic Seas and Atlantic subpolar basins may in turn act as a feedback on climate [Rahmstorf, 2002; Clark et al., 2002]. More specifically, increasing freshwater inputs may slow North Atlantic Deep Water (NADW) formation, a major driver of Atlantic meridional overturning circulation (MOC). Redistribution of heat by MOC helps to moderate differences in surface air temperatures between low and high latitudes, and therefore a slowing or cessation of MOC in response to global warming could lead to relative cooling in some regions and amplified warming in others [Rahmstorf, 2002]. How may changes in arctic and subarctic river discharge affect MOC?

[4] Although it is clear that there are large regional differences in river discharge trends within the Arctic and subarctic, quantitative comparison of the Eurasian and $\mathrm{N}$. American findings has been hampered by differences in the time periods and analytical methods used in the various studies. Here we compare changes in river discharge from different regions of the pan-arctic watershed (Figure 1) using identical time periods (1964-2000) and analytical methods.

\section{Data and Methods}

[5] Discharge records from 16 Eurasian rivers and $56 \mathrm{~N}$. American rivers were analyzed (see auxiliary material ${ }^{1}$ for names, locations, watershed areas, and average discharge). The Eurasian data are from R-ArcticNet (http://www. r-arcticnet.sr.unh.edu/) and Arctic RIMS (http://rims/ unh.edu) and the N. American data are from the Water Survey of Canada's Hydrometric Database- HYDAT (http://www.wsc.ec.gc.ca/). Fourteen of the 56 N. American rivers flow into the Arctic Ocean (hereafter referred to as $\mathrm{N}$. American arctic rivers) and 42 flow into HJUBs. Relative to the comprehensive estimates of Lammers et al. [2001], the 16 Eurasian rivers account for about $74 \%$ of total discharge from Eurasia to the Arctic Ocean whereas the $14 \mathrm{~N}$. American arctic rivers account for about $85 \%$ of total discharge from N. America to the Arctic Ocean. The 42 rivers flowing into HJUBs account for about $82 \%$ of total discharge to HJUBs.

\footnotetext{
${ }^{1}$ Auxiliary material is available at $\mathrm{ftp}: / / \mathrm{ftp}$.agu.org/apend/g1/ $2005 \mathrm{~g} 1025753$.
} 


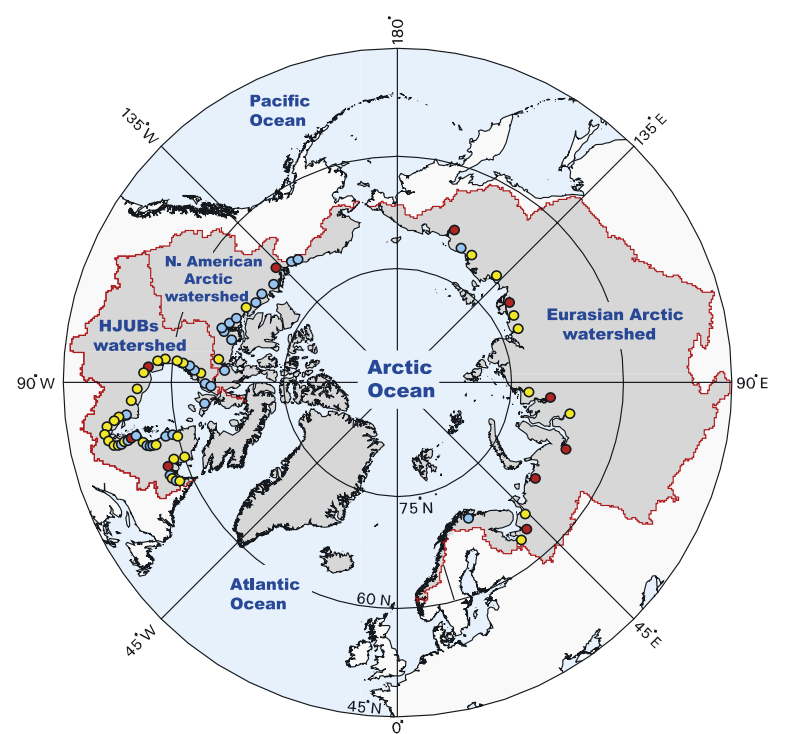

Figure 1. Watersheds of the Arctic Ocean and Hudson, James, and Ungava Bays (HJUBs). Colored points mark the mouths of the 72 rivers included in this study. Blue $=<6 \mathrm{~km}^{3} / \mathrm{y}$. Yellow $=6$ to $<60 \mathrm{~km}^{3} / \mathrm{y}$. Red $=60$ to $600 \mathrm{~km}^{3} / \mathrm{y}$.

[6] Records from gauging stations at downstream locations were used as a basis for our analysis. Data are available from downstream stations on major Eurasian and N. American rivers during most years from 1964-2000. Values for missing years were interpolated. Data sets from downstream locations on some of the smaller rivers are less complete. In these cases, discharge estimates at downstream locations were derived from data collected upstream. Details on temporal coverage and gauge locations for HJUBs rivers and for the 6 largest Eurasian rivers are given by Déry et al. [2005] and Peterson et al. [2002], respectively. Data sets on the remaining N. American rivers are discussed by Déry and Wood [2005]. Data sets for the 10 smaller Eurasian rivers have not been discussed in previous publications (see auxiliary material for details).

[7] Filling of reservoirs after dam construction on several of the rivers caused temporary decreases in discharge. To explore the influence of these temporary decreases on long-term trends in discharge, we added back the missing water as fractions of total reservoir volume spread evenly over the years of filling and compared the resultant data to the observed discharge. Long-term changes in water-use related to storage in reservoirs are not accounted for in this analysis. Water diversions in the HJUBs region have also influenced discharge, causing decreases in some rivers and increases in others [Déry et al., 2005]. Therefore, stations upstream of the diversion-influenced sections of HJUBs rivers were used in our analysis.

[8] Analyses of long-term trends in both the observed and adjusted data were done using the Mann-Kendall test, with linear changes in the data represented by Kendall-Theil Robust Lines. This non-parametric approach is well suited for evaluating changes in hydrologic regimes [Ziegler et al., 2003; Déry et al., 2005]. The appendix of Déry et al. [2005] provides a concise explanation of the statistics as applied to river discharge data.

\section{Results}

[9] Discharge to the Arctic Ocean increased by $5.6 \mathrm{~km}^{3} / \mathrm{y} / \mathrm{y}$ during 1964-2000 (Figure 2a), a cumulative change amounting to $208 \mathrm{~km}^{3} / \mathrm{y}$ greater discharge at the end of the period as compared to the beginning. A large increase in Eurasian arctic river discharge (Figure $2 \mathrm{~b}$ ) was only slightly offset by a decrease in N. American arctic river discharge (Figure 2c). The six largest Eurasian arctic rivers accounted for $87 \%$ of the change in discharge from Eurasia to the Arctic Ocean (Table 1). Expressed relative to size, however, discharge from the ten smaller Eurasian arctic rivers changed at a rate that was similar to that observed for the 6 largest Eurasian arctic rivers (Table 1). Filling of reservoirs did not have a major influence on the long-term trends, but was more important in Eurasia than N. America (Figure 2).

[10] In contrast to the net increase in river discharge to the Arctic Ocean, discharge to HJUBs decreased by about $2.5 \mathrm{~km}^{3} / \mathrm{y} / \mathrm{y}$ during 1964-2000 (Figure 3), a cumulative change amounting to $92 \mathrm{~km}^{3} / \mathrm{y}$ less discharge at the end of the period as compared to the beginning. As with discharge to the Arctic Ocean, filling of reservoirs did not have a major influence on the long-term trend (Figure 3).

[11] River discharge to the Bering Sea is not included in this analysis because of limited data. Even the Yukon River, the largest in the region, was not consistently monitored at downstream locations during 1964-2000. Nonetheless, we did reconstruct discharge from the Yukon River using data from upstream stations. Analysis of these data showed no significant change in discharge (slope of Kendall-Theil Robust line $=0.4 \mathrm{~km}^{3} / \mathrm{y} / \mathrm{y}, \mathrm{p}=0.1$ )

[12] Overall, there was a net increase in river discharge amounting to $3.2 \mathrm{~km}^{3} / \mathrm{y} / \mathrm{y}$ over the $1964-2000$ period (Table 1, sum of all sources). Cumulatively, this year-to-

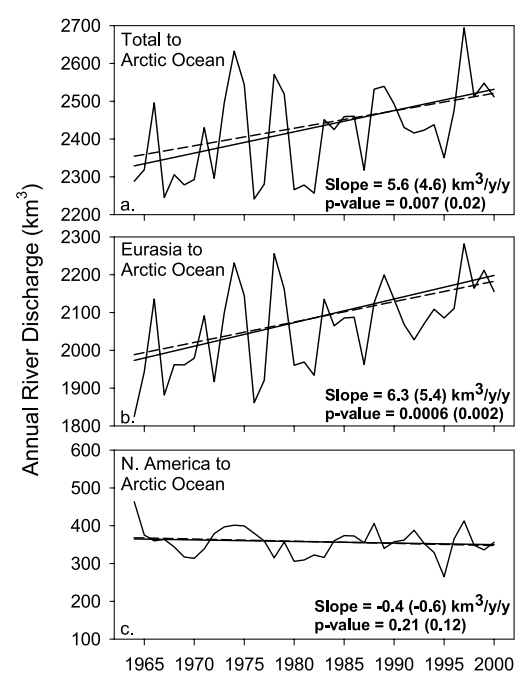

Figure 2. River discharge to the Arctic Ocean from 1964 through 2000. Linear trends are represented by KendallTheil Robust Lines with p-values determined using the Mann-Kendall test. Dashed lines and values shown in parentheses reflect adjustments made to remove discharge deficits from years of reservoir filling. 
Table 1. Averages and Changes in Discharge to the Arctic Ocean and HJUBs for $1964-2000^{\mathrm{a}}$

\begin{tabular}{|c|c|c|c|c|}
\hline Input & $\begin{array}{l}\text { Average Combined } \\
\text { Discharge, } \mathrm{km}^{3} / \mathrm{y}\end{array}$ & $\begin{array}{c}\text { Annual Change, } \\
\mathrm{km}^{3} / \mathrm{y} / \mathrm{y}\end{array}$ & $\begin{array}{c}\text { Cumulative Change, } \\
\mathrm{km}^{3} / \mathrm{y} \text { over } 37 \mathrm{y}\end{array}$ & $\begin{array}{c}\text { Cumulative Change, } \\
\% \text { over } 37 \mathrm{y}\end{array}$ \\
\hline \multicolumn{5}{|l|}{ Eurasia to Arctic O. } \\
\hline Six largest rivers & 1839 (1847) & $5.34(4.57)$ & $198(169)$ & $11.3(9.6)$ \\
\hline Ten smaller rivers & 224 & 0.80 & 29 & 14.3 \\
\hline N. America to Arctic O. & $357(359)$ & $-0.41(-0.57)$ & $-15(-21)$ & $-4.2(-5.8)$ \\
\hline N. America to HJUBs & $717(722)$ & $-2.49(-2.41)$ & $-92(-89)$ & $-12.1(-11.6)$ \\
\hline
\end{tabular}

year increase translates into approximately $120 \mathrm{~km}^{3} / \mathrm{y}$ greater discharge at the end of the period as compared with the beginning.

\section{Discussion}

[13] Déry et al. [2005] noted that decreases in river discharge from N. America to HJUBs between 1964 and 2000 largely balanced longer-term (1936-1999) changes in Eurasian arctic river discharge [Peterson et al., 2002]. However, differences in time periods and methods of analysis used to evaluate discharge trends from Eurasia and N. America confounded the comparison. Now, in a side-by-side comparison we find that decreasing discharge to HJUBs does not balance increasing discharge from Eurasia to the Arctic Ocean (Table 1). Discharge from the six largest Eurasian rivers (the rivers included by Peterson et al. [2002]) between 1964 and 2000 increased at more than twice the rate observed over 1936-1999. Inclusion of smaller rivers in the analysis added still more to the observed increase in Eurasian river discharge.

[14] Our finding that reservoir filling had relatively little effect on long-term trends in annual discharge is consistent with earlier reports on the N. American [Déry and Wood, 2005] and Eurasian [Ye et al., 2003; Yang et al., 2004; McClelland et al., 2004] rivers. However, it is noteworthy that the reservoir-filling correction applied to the Eurasian rivers in the present study had an effect that was opposite in sign to that found in the earlier studies. The simplest explanation for this difference is that reservoir filling primarily occurred during 1956-1980. This pulled annual discharge values down during the first half of 1964-2000 causing the measured increase to be marginally higher than it would have been in the absence of reservoir filling. The earlier studies considered changes from 1936-1999 [Ye et al., 2003; Yang et al., 2004; McClelland et al., 2004], and thus filling of the same reservoirs pulled annual discharge values down starting in the middle and extending into the second half of the longer analysis period. It is also possible that long-term changes in water-use related to storage in reservoirs account for some of the difference in findings between the present and earlier studies, as more comprehensive naturalization methods were used to correct for reservoir effects in the earlier studies [Ye et al., 2003; Yang et al., 2004; McClelland et al., 2004].

[15] Similar percentage increases in discharge from the smaller and larger Eurasian rivers (Table 1) suggest that an overarching mechanism may account for the changes. This is remarkable given that the drainage areas of the smaller rivers are primarily confined to the Arctic whereas the drainage areas of the larger rivers extend much farther south. The consistency of the trends supports extrapolation to the ungauged portion of the Eurasian arctic watershed. Likewise, it is reasonable to assume that discharge from ungauged rivers within the N. American arctic and HJUBs watersheds has, on average, changed along with discharge from the gauged rivers.

[16] Potential linkages between climate variables and the observed changes in river discharge are the subject of ongoing debate. Relationships with various teleconnection indices (North Atlantic Oscillation, Arctic Oscillation, El Niño/Southern Oscillation, Pacific Decadal Oscillation) have been identified [Peterson et al., 2002; Déry and Wood, 2005]. However, these indices themselves are related such that identifying a primary correlate is difficult. Furthermore, global warming may be altering the oscillation patterns of various indices [Shindell et al., 1999]. With respect to changes in Eurasian arctic river discharge, Peterson et al. [2002] showed strong correlations with both global surface air temperature and the NAO index. In recent years, however, the NAO and associated Northern Annular Mode (NAM) indices have retreated to more neutral values [Serreze and Francis, 2006] while warming and Eurasian arctic river discharge have continued to increase.

[17] Net precipitation at high latitudes is expected to increase with global warming [Cubasch et al., 2001], and indeed recent runs of the HadCM3 global circulation model showed increases in Eurasian river discharge to the Arctic Ocean during the latter half of the 20th century that were very similar to the observed changes [Wu et al., 2005]. Our present findings for the six largest Eurasian arctic rivers from 1964-2000 remain consistent with those of Wu et al. [2005]. Furthermore, by scaling up our findings for Eurasia and N. America to account for the 26\% (Eurasia) and $15 \%$ (N. America) of discharge to the Arctic Ocean not included in our analysis, we arrive at an estimated change of $7.4 \mathrm{~km}^{3} / \mathrm{y} / \mathrm{y}$ that approaches the $8.7 \mathrm{~km}^{3} / \mathrm{y} / \mathrm{y}$ change reported by $W u$ et al. [2005] for rivers flowing into the

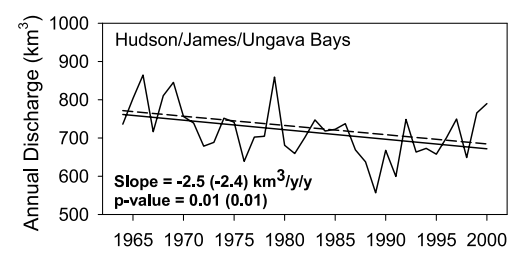

Figure 3. River discharge to HJUBs from 1964 through 2000. Linear trends are represented by Kendall-Theil Robust Lines with p-values determined using the MannKendall test. Dashed lines and values shown in parentheses reflect adjustments made to remove discharge deficits from years of reservoir filling. 
ocean above $65^{\circ} \mathrm{N}$ from $1960-2001$. The rivers flowing into HJUBS fall below the $65^{\circ} \mathrm{N}$ threshold set by $W u$ et al. [2005], and thus are not included in the comparison. However, concomitant decreases in precipitation and river discharge in the HJUBs region from 1964-2000 also support changes in precipitation as a primary driver of changes in discharge [Déry et al., 2005].

[18] While the empirical data and GCM results discussed above show remarkable agreement, it should be noted that precipitation estimates for Eurasia do not consistently show increases that would explain the increasing river discharge [Berezovskaya et al., 2004]. This has fueled a lively debate about the need for bias corrections related to winter precipitation, the validity of interpolation routines, and the robustness of reanalysis products [Pavelsky et al., 2005; Razuvaev et al., 2005]. At the same time, researchers have been looking into alternative mechanisms such as changes in permafrost and fires that may link warming with the observed increases in Eurasian arctic river discharge [McClelland et al., 2004, Zhang et al., 2005]

[19] Regardless of the particular mechanism(s) behind the changes in discharge, this evaluation highlights the need to understand the consequences of adding or removing freshwater from particular regions of the arctic and subarctic oceans. We expect decreasing river discharge to HJUBs and increasing river discharge to the Arctic Ocean to have opposing effects on NADW formation. However, NADW formation may be more sensitive to changes in freshwater inputs from some regions than others. A recent modeling effort by Myers [2005] showed that most of the freshwater supplied to the interior of the Labrador Sea comes from the West Greenland/Irminger Current system, while waters from Hudson Bay and the Canadian Arctic Archipelago are primarily transported south of the basin via the Labrador Current. Thus, a change in river discharge to HJUBs should have less of an influence on NADW formation than a comparable change in river discharge to the Arctic Ocean.

[20] The observed changes in river discharge over 19642000 amount to an increase of about $0.007 \mathrm{~Sv}$ to the Arctic Ocean and a decrease of about $0.003 \mathrm{~Sv}$ to HJUBs by the end of the record. These values are relatively small compared to the $\sim 0.1 \mathrm{~Sv}$ that lead to abrupt reductions in NADW formation in a variety of models [Clark et al., 2002; Rahmstorf, 2002]. However, combined with changes in net precipitation on the ocean's surface and melting of glaciers and sea ice, changes in river discharge do make a significant contribution to mounting freshwater anomalies in the arctic and subarctic domains (B. Peterson et al., Acceleration of the arctic and subarctic freshwater cycle, submitted to Science, 2006). In the future, freshwater contributions from river discharge, net precipitation on the ocean's surface, and glaciers (particularly the Greenland Ice Sheet) are expected to increase while contributions from melting sea-ice stocks become less important [ACIA, 2005].

[21] Acknowledgment. This work was supported by the Arctic System Science Program of the National Science Foundation (NSF-OPP0229302, NSF-OPP-0230211, NSF-OPP-0519840) and by the National Oceanic and Atmospheric Administration (NA17RJ2612).

\section{References}

ACIA (2005), Arctic Climate Impact Assessment, 1042 pp., Cambridge Univ. Press, New York.
Berezovskaya, S., D. Yang, and D. L. Kane (2004), Compatibility analysis of precipitation and runoff trends over the large Siberian watersheds, Geophys. Res. Lett., 31, L21502, doi:10.1029/2004GL021277.

Clark, P. U., N. G. Pisias, T. F. Stocker, and A. J. Weaver (2002), The role of the thermohaline circulation in abrupt climate change, Nature, 415, $863-869$

Cubasch, U., et al (2001), Projections of future climate change, in Climate Change 2001: The Scientific Basis, Contribution of Working Group 1 to the Third Assessment Report of the Intergovernmental Panel on Climate Change, edited by J. T. Houghton et al., pp. 525-582, Cambridge Univ. Press, New York.

Déry, S. J., and E. F. Wood (2005), Decreasing river discharge in northern Canada, Geophys. Res. Lett., 32, L10401, doi:10.1029/2005GL022845.

Déry, S. J., M. Stieglitz, E. C. McKenna, and E. F. Wood (2005), Characteristics and trends of river discharge into Hudson, James, and Ungava Bays, 1964-2000, J. Clim., 18, 2540-2557.

Lammers, R. B., A. I. Shiklomanov, C. J. Vörösmarty, B. M. Fekete, and B. J. Peterson (2001), Assessment of contemporary Arctic river runoff based on observational discharge records, J. Geophys. Res., 106(D4), $3321-3334$

McClelland, J. W., R. M. Holmes, B. J. Peterson, and M. Stieglitz (2004), Increasing river discharge in the Eurasian Arctic: Consideration of dams, permafrost thaw, and fires as potential agents of change, J. Geophys. Res., 109, D18102, doi:10.1029/2004JD004583.

Myers, P. G. (2005), Impact of freshwater from the Canadian Arctic Archipelago on Labrador Sea Water formation, Geophys. Res. Lett., 32, L06605, doi:10.1029/2004GL022082.

Pavelsky, T. M., L. C. Smith, K. Sampson, R. Lammers, A. Shiklomanov, and G. MacDonald (2005), A statistical analysis of precipitation and river discharge variability in the Eurasian Arctic, Eos Trans. $A G U, 86$, Fall Meet. Suppl., Abstract U41A-0807.

Peterson, B. J., R. M. Holmes, J. W. McClelland, C. J. Vörösmarty, R. B. Lammers, A. I. Shiklomanov, I. A. Shiklomanov, and S. Rahmstorf (2002), Increasing river discharge to the Arctic Ocean, Science, 298, $2171-2173$.

Rahmstorf, S. (2002), Ocean circulation and climate during the past 120,000 years, Nature, 419, 207-214.

Razuvaev, V., P. Y. Groisman, O. N. Bulygina, E. G. Bogdanova, B. M. Ilijn, J. G. Enloe, and E. S. Yarosh (2005), Comprehensive bias-free precipitation archive for northern Eurasia: What can it declare about changes in the arctic freshwater system?, Eos Trans. $A G U, 86$, Fall Meet. Suppl., Abstract U41A-0811.

Serreze, M. C., and J. A. Francis (2006), The Arctic amplification debate, Clim. Change, doi:10.1007/s10584-005-9017-y, in press.

Shindell, D. T., R. L. Miller, G. A. Schmidt, and L. Pandolfo (1999), Simulation of recent northern winter climate trends by greenhouse-gas forcing, Nature, 399, 452-455.

Stocker, T. F., and C. C. Raible (2005), Water cycle shifts gear, Nature, 434, $830-832$.

Wu, P., R. Wood, and P. Stott (2005), Human influence on increasing Arctic river discharges, Geophys. Res. Lett., 32, L02703, doi:10.1029/ 2004GL021570.

Yang, D., B. Ye, and A. Shiklomanov (2004), Streamflow characteristics and changes over the Ob River watershed in Siberia, J. Hydrometeorol., 5(4), 69-84.

Ye, B., D. Yang, and D. L. Kane (2003), Changes in Lena River streamflow hydrology: Human impacts versus natural variations, Water Resour. Res., 39(7), 1200, doi:10.1029/2003WR001991.

Zhang, T., O. W. Frauenfeld, R. G. Barry, A. Etinger, J. McCreight, and D. Gilichinksy (2005), Response of changes in active layer and permafrost conditions to hydrological cycle in the Russian Arctic, Eos Trans. $A G U, 86$, Fall Meet. Suppl., Abstract C21C-1118.

Ziegler, A. D., J. Sheffield, E. P. Maurer, B. Nijssen, E. F. Wood, and D. P. Lettenmaier (2003), Detection of intensification in global- and continental-scale hydrological cycles: Temporal scale of evolution, J. Clim., 16, $535-547$.

S. J. Déry, Department of Environmental Science and Engineering, University of Northern British Columbia, Prince George, BC, Canada V2N 4Z9.

R. M. Holmes, Woods Hole Research Center, Woods Hole, MA 02543 , USA.

J. W. McClelland, Marine Science Institute, University of Texas, Port Aransas, TX 78373, USA. (jimm@utmsi.utexas.edu)

B. J. Peterson, Marine Biological Laboratory, Woods Hole, MA 02543, USA.

E. F. Wood, Department of Civil and Environmental Engineering, Princeton University, Princeton, NJ 08544, USA. 